2. The number of reactive $\mathrm{SH}$ groups/molecule in the haemoglobins studied approximate either to 2 or to 4 .

3. The behaviour of the reactive $\mathrm{SH}$ groups differs from that of cysteine in three ways: $(a)$ the rate of reaction of heavy-metal ions with the reactive SH groups is slower than with cysteine; (b) thiosulphate interferes with the reaction between $\mathrm{Ag}^{+}$ions and the reactive $\mathrm{SH}$ groups of human haemoglobin, but not with cysteine; (c) the acid-base-titration curves of human haemoglobin in the presence and absence of phenylmercuric hydroxide suggest that the reactive $\mathrm{SH}$ groups are not ionized at $\mathrm{pH}$ values less than 10 .

The author wishes to thank Dr R. Cecil for his advice and interest in this work, and also the Thomas Lawrence Pawlett Trustees and the Commonwealth Scientific and
Industrial Research Organization for a grant. This work was supported by grants from the U.S. Public Health Service and the Rockefeller Foundation.

\section{REFERENCES}

Allison, A. C. \& Cecil, R. (1958). Biochem. J. 69, 27.

Benesch, R. \& Benesch, R. E. (1960). Fed. Proc. 19, 78.

Benesch, R. \& Benesch, R. E. (1961). J. biol. Chem. 236, 405.

Benesch, R. E. \& Benesch, R. (1955). J. Amer. chem. Soc. 77, 5877.

Cecil, R. \& McPhee, J. R. (1959). Advanc. Protein Chem. 14, 255.

Cecil, R. \& Snow, N. S. (1962). Biochem. J. 82, 247.

Riggs, A. F. (1959). Nature, Lond., 183, 1037.

Riggs, A. F. (1960). J. gen. Physiol. 43, 737.

Riggs, A. F. \& Wolbach, R. A. (1956). J. gen. Physiol. 39, 585.

Biochem. J. (1962) 84, 364

\title{
Acute Toxic Liver Injury
}

\section{NICOTINAMIDE-ADENINE DINUCLEOTIDE-PYROPHOSPHORYLASE ACTIVITY OF NUCLEI ISOLATED FROM RAT LIVER IN HELIOTRINE AND IN DIMETHYLNITROSAMINE POISONING}

\author{
By G. S. CHRISTIE, M. J. BAILIE AND R. N. LE PAGE \\ Department of Pathology, University of Melbourne, Parkville, N. 2, Victoria, Australia
}

(Received 23 January 1962)

Manometric studies on homogenate and mitochondrial preparations from the livers of rats poisoned with heliotrine (Christie, 1958) and with dimethylnitrosamine (Bailie \& Christie, 1959) showed that an apparent deficiency of NAD developed during the course of the toxic process. Decreased concentrations of both NAD and NADP have since been demonstrated in homogenates and in the mitochondrial and supernatant fractions from livers of rats treated with heliotrine for 17$20 \mathrm{hr}$. (Christie, Le Page \& Bailie, 1961; Christie \& Le Page, 1962 $a$ ) and with dimethylnitrosamine for 14 hr. (Bailie, 1959; M. J. Bailie, G. S. Christie \& R. N. Le Page, unpublished work). Also the capacity of the liver to synthesize NAD in vivo in 'response' to a single large dose of nicotinamide appeared to decrease with increasing duration of pretreatment of the rats with heliotrine (Christie \& Le Page, 1962b); the possibility remained, however, that the apparent decrease of synthesis was not real but arose from losses of liver coenzymes which were known to be occurring. It seemed that measurements of the NAD-pyrophosphorylase activity of nuclei isolated from the livers of rats poisoned with heliotrine or with dimethylnitros- amine might help to show whether a real interference with NAD synthesis occurred.

NAD pyrophosphorylase (Kornberg, 1950) converts NMN into NAD and appears to be indisting. uishable from the enzyme which converts nicotinic acid mononucleotide into nicotinic acid-adenine dinucleotide in the three-step pathway of NAD synthesis proposed by Preiss \& Handler (1958 $a, b)$. The enzyme is localized in the nucleus (Hogeboom \& Schneider, 1952). Low activities of the enzyme have been observed in nuclei isolated from certain rapidly-growing tissues, e.g. spontaneous and induced tumours, foetal-mouse liver and regenerating rat liver (Branster \& Morton, 1956; Morton, 1958; Stirpe \& Aldridge, 1961); but 'little change was found' in preparations from livers of rats treated with the liver poisons carbon tetrachloride, dimethylnitrosamine or ethionine (Stirpe \& Aldridge, 1961). However, Stirpe \& Aldridge (1961) observed a significant fall of activity with beryllium.

The observations presented below show that NAD-pyrophosphorylase activity was significantly decreased $18 \mathrm{hr}$. after administration of heliotrine, but not $19 \mathrm{hr}$. after administration of dimethylnitrosamine. 


\section{MATERIALS AND METHODS}

Animals. Adult male hooded Wistar rats (270-330 g.) were used with heliotrine, as in previous studies (Christie, 1958; Christie \& Le Page, $1962 a, b)$. Adult male or female Sprague-Dawley rats (150-250 g.) (Bailie \& Christie, 1959) were used with dimethylnitrosamine. Heliotrine $(320 \mathrm{mg}$./ kg. body wt., in aqueous solution neutralized to $\mathrm{pH} \mathbf{7 \cdot 3}$ with $\mathrm{HCl})$, or dimethylnitrosamine $(100 \mathrm{mg} . / \mathrm{kg}$. body wt., in aqueous solution) was injected intraperitoneally under light ether anaesthesia. Control rats received injections of aq. $0.9 \%$ sodium chloride.

Reagents. Inorganic and common organic reagents were of analytical or laboratory grade. Ethanol was benzenefree and was redistilled over alkali. Nicotinamide was obtained from L. Light and Co. Ltd., Colnbrook, Bucks., and ATP, NAD and crystalline alcohol dehydrogenase from Sigma Chemical Co., St Louis, Mo., U.S.A. Potato pyrophosphatase was kindly supplied by Professor R. K. Morton, Department of Agricultural Chemistry, Waite Research Institute, Adelaide, South Australia. The preparation of NMN from NAD by means of potato pyrophosphatase, and the estimation of NMN, were carried out by the methods described by Branster \& Morton (1956). Dimethylnitrosamine was prepared by the method of Hatt (1946).

Tissue preparations. Rats were killed by stunning and exsanguination, and the livers were rapidly removed and chilled in ice-cold aqueous medium ( $0.25 \mathrm{M}$-sucrose, $1.8 \mathrm{mM}$ $\mathrm{CaCl}_{2}$ ). After the chilling, the liver surface was blotted, and the whole liver weighed; a whole lobe (about $3 \mathrm{~g}$.) was then excised, weighed accurately and perfused (via the hepatic vein) with cold $0.25 \mathrm{M}$-sucrose-1.8 $\mathrm{mm}-\mathrm{CaCl}_{2}$ soln. until the lobe was uniformly pale and the effluent clear. Homogenates $\left[20 \%(w / v)\right.$ in $0.25 \mathrm{M}$-sucrose-1.8 mM- $\mathrm{CaCl}_{2}$ soln.] were made at $0-1^{\circ}$ in a Potter-Elvehjem all-glass powerdriven homogenizer. The homogenates were strained through 15-denier nylon to remove fragments of fibrous tissue. Nuclei were isolated from the homogenates by a method similar to that of Hogeboom, Schneider \& Striebich (1952). In the initial isolation, $10 \mathrm{ml}$. of homogenate was layered over $20 \mathrm{ml}$. of $0.34 \mathrm{M}$-sucrose- $0.18 \mathrm{~mm}-\mathrm{CaCl}_{2}$ soln. and centrifuged $(700 \mathrm{~g}$ for $20 \mathrm{~min}$.). The sedimented pellet was resuspended in $0.25 \mathrm{M}$-sucrose- $0.18 \mathrm{~mm}-\mathrm{CaCl}_{2}$ soln., and the volume adjusted to $10 \mathrm{ml}$; the suspension was then relayered as before and centrifuged (700 $\mathrm{g}$ for $10 \mathrm{~min}$.); the pellet was finally resuspended in $0.25 \mathrm{M}$-sucrose-0. $0.18 \mathrm{mM}$ $\mathrm{CaCl}_{2}$ soln. to give a final volume of $5 \mathrm{ml}$.

Measurement of synthesis of nicotinamide-adenine dinucleotide. The procedure followed was essentially that of Kornberg (1950). The reaction mixture contained NMN (4 $\mu$ moles), glycylglycine buffer, pH $7 \cdot 2$ (75 $\mu$ moles), ATP (10 $\mu$ moles), $\mathrm{MgCl}_{2}$ (15 $\mu$ moles), nicotinamide (300 $\mu$ moles), nuclear suspension $(0.2$ or $0.3 \mathrm{ml}$. samples), and water to give a final volume of $1 \mathrm{ml}$. All the components except the nuclear suspension were added to the reaction tubes, but the blanks also received $1.5 \mathrm{ml}$. of $0.5 \mathrm{~N}$-trichloroacetic acid. All tubes were shaken $\left(4 \mathrm{~min}\right.$. at $37^{\circ}$ ) in a Warburg bath, the samples of nuclear suspension were added, and incubation was continued for a further $15 \mathrm{~min}$. The tubes were of $12 \mathrm{~mm}$. internal diameter and a shaking speed of 120 strokes/min. was necessary for the optimum mixing required for maximum reaction rates. Duplicate reaction tubes were incubated for each concentration of nuclear suspension, accompanied by duplicate blanks. The reaction was stopped by adding $1.5 \mathrm{ml}$. of $0.5 \mathrm{~N}$-trichloroacetic acid to each tube except the blanks. All tubes were then immediately chilled and centrifuged at $0^{\circ}$, and a sample $(0.2 \mathrm{ml}$.) of the supernatant from each was transferred to a fresh tube and neutralized with $2 \mathrm{~N}-\mathrm{NaOH}$. Glycine buffer $(0 \cdot 2 \mathrm{M})$, pH 9.6, containing $0.3 \mathrm{M}$-ethanol, was added to give a final volume of $7 \mathrm{ml}$. The extinction (at $340 \mathrm{~m} \mu$ ) of each sample was measured, in a Unicam SP. 500 spectrophotometer with a cuvette with a $4 \mathrm{~cm}$. light-path, before and after the addition of alcohol dehydrogenase; the NAD concentrations in the reaction tubes and blanks were calcuated from the extinction differences by using an extinction coefficient of $6.22 \times 10^{6} \mathrm{~cm} .{ }^{2} / \mathrm{mole}$ (Horecker \& Kornberg, 1948). The amount of NAD synthesized in the reaction tubes was calculated by subtraction of the blank values. Linear relationships were found between the amount of NAD synthesized and the size of the nuclear sample, and the duration of incubation. Extinction differences were about $0.15-0.25$ in the reaction tubes and $0.02-0.04$ in the blanks.

Counting of nuclei. A sample (1 ml.) of nuclear suspension was diluted to $10 \mathrm{ml}$. with an aqueous solution containing $0.25 \mathrm{M}$-sucrose, $0.18 \mathrm{~mm}-\mathrm{CaCl}_{2}, 1.5 \%(v / v)$ acetic acid and $0.02 \%$ gentian violet. Nuclei were counted in a Hawksley haemocytometer chamber with double Neubauer rulings; about 1000 nuclei were counted from each preparation. Satisfactory nuclear counting required standardiza. tion of all steps. Acetic acid in the diluting fluid was of value because its fixative action on the nuclei helped to preserve their structure and its lytic action on erythrocytes and cytoplasmic residues assisted in accurate identification of nuclei. Light staining of the nuclei by gentian violet was also of value; some damaged nuclei stained poorly but could still be identified by their structure, and were included in the counts; obviously damaged nuclei amounted to a quarter of the count in preparations from rats treated for $18 \mathrm{hr}$. with either heliotrine or dimethylnitrosamine. The degree of contamination of the nuclear suspensions with erythrocytes and unbroken liver cells was estimated in several control preparations, and was within the limits quoted by Hogeboom \& Schneider (1952).

\section{RESULTS}

Results from determination of rates of NAD synthesis by isolated liver-cell nuclei from control and heliotrine-treated Wistar rats are given in Table 1, and are expressed as NAD synthesized/hr./ $10^{\circ}$ nuclei and as NAD synthesized/hr./liver/100 g. body wt. With either unit, a significant decrease in the rate of NAD synthesis was observed after treatment of the rats with heliotrine for $18 \mathrm{hr}$. The columns of Table 1 showing the ratio (mean treated value):(mean control value) indicate that a trend of diminishing NAD synthesis with increasing time of treatment with heliotrine was apparent in both sets of results before $18 \mathrm{hr}$.

Results from the experiments with dimethylnitrosamine are given in Table 2. Although at $19 \mathrm{hr}$. the mean treated value was lower than the mean control value, the decrease in the rate of NAD 
Table 1. Rate of synthesis of nicotinamide-adenine dinucleotide by isolated liver-cell nuclei from control and heliotrine-treated Wistar rats

\begin{tabular}{|c|c|c|c|c|c|}
\hline $\begin{array}{l}\text { Duration of } \\
\text { heliotrine } \\
\text { treatment } \\
\text { (hr.) }\end{array}$ & $\begin{array}{l}\text { No. of } \\
\text { rats }\end{array}$ & $\begin{array}{c}\text { NAD } \\
\underset{\text { nuclei })}{\mu \mathrm{moles} / \mathrm{hr} . / 10^{9}} \\
\text { nucl }\end{array}$ & $\left(\begin{array}{c}\text { Ratio } \\
\left(\frac{\text { mean treated value }}{\text { mean control value }}\right)\end{array}\right.$ & $\begin{array}{c}\text { NAD } \\
\text { ( } \mu \text { moles/hr./liver/ } \\
100 \text { g. body wt.) }\end{array}$ & $\left(\begin{array}{c}\text { Ratio } \\
\left(\frac{\text { mean treated value }}{\text { mean control value }}\right)\end{array}\right.$ \\
\hline $\begin{array}{l}0 \\
7 \\
11 \\
14 \frac{1}{2} \\
17 \\
18 \\
19\end{array}$ & $\begin{array}{l}8 \\
1 \\
2 \\
2 \\
1 \\
1 \\
1\end{array}$ & $\begin{array}{l}21 \cdot 4 \pm 0 \cdot 97 \\
24 \cdot 2 \\
17 \cdot 8 \pm 1 \cdot 35 \\
18 \cdot 6 \pm 0 \cdot 91 \\
18 \cdot 4^{*} \\
15 \cdot 9 \dagger \\
13 \cdot 1 \dagger\end{array}$ & $\begin{array}{l}1 \cdot 00 \pm 0.05 \\
1 \cdot 13 \\
0 \cdot 83 \pm 0.06 \\
0.87 \pm 0.04 \\
0.86 \\
0.74 \\
0.61\end{array}$ & $\begin{array}{l}\mathbf{9 \cdot 6} \pm 0 \cdot 39 \\
\mathbf{9 \cdot 4} \\
\mathbf{7 \cdot 0} \pm 0 \cdot 65 \\
9 \cdot 0 \pm 0 \cdot 41 \\
\mathbf{7 \cdot 1 \dagger} \\
\mathbf{5 \cdot 4} \dagger \\
\mathbf{6} \cdot \mathbf{5} \dagger\end{array}$ & $\begin{array}{l}1 \cdot 00 \pm 0.04 \\
0.98 \\
0.73 \pm 0.07 \\
0 \cdot 94 \pm 0.04 \\
0.74 \\
0 \cdot 56 \\
0.68\end{array}$ \\
\hline & & $* P<0.02$ ( $t$ test $)$ & \multicolumn{3}{|c|}{$\dagger P<0.001$ ( $t$ test $).$} \\
\hline
\end{tabular}

Table 2. Rate of synthesis of nicotinamide-adenine dinucleotide by isolated liver-cell nuclei from control and dimethylnitrosamine-treated Sprague-Dawley rats

$\begin{array}{ccc}\begin{array}{c}\text { Duration of } \\ \text { dimethyl- } \\ \text { nitrosamine } \\ \begin{array}{c}\text { treatment } \\ \text { (hr.) }\end{array}\end{array} & \begin{array}{c}\text { No. of } \\ \text { rats }\end{array} & \begin{array}{c}\text { NAD } \\ \text { ( } \mathrm{moles} / \mathrm{hr} . / 10^{9} \\ \text { nuclei) }\end{array} \\ 0 & 9 & 16 \cdot 1 \pm 0.57 \\ 54 & 1 & 17 \cdot 6 \\ 11 \frac{3}{4} & 4 & 16.5 \pm 1.85 \\ 17 \frac{1}{2} & 1 & 14 \cdot 3 \\ 19 & 2 & 14 \cdot 1^{*} \pm 1.91 \\ & & * P>0 \cdot 1(t \text { test }) .\end{array}$

Ratio
$\left(\begin{array}{c}\text { mean treated value } \\ \hline \text { mean control value }\end{array}\right)$
$1 \cdot 0 \pm 0 \cdot 04$
$1 \cdot 09$
$1 \cdot 02 \pm 0 \cdot 11$
$0 \cdot 89$
$0 \cdot 87 \pm 0 \cdot 12$

\begin{tabular}{|c|c|}
\hline $\begin{array}{c}\text { NAD } \\
\text { ( } \mu \text { moles/hr./liver/ } \\
100 \text { g. body wt.) }\end{array}$ & $\begin{array}{c}\text { Ratio } \\
\left(\frac{\text { mean treated value }}{\text { mean control value }}\right)\end{array}$ \\
\hline $\begin{array}{l}11 \cdot 9 \pm 0 \cdot 67 \\
11 \cdot 4 \\
11 \cdot 2 \pm 0 \cdot 90 \\
12 \cdot 4 \\
9 \cdot 7 \dagger \pm 0 \cdot 08\end{array}$ & $\begin{array}{l}1.0 \pm 0.06 \\
0.96 \\
0.94 \pm 0.08 \\
1.04 \\
0.82 \pm 0.01\end{array}$ \\
\hline
\end{tabular}

synthesis was not statistically significant relative to nuclear count, although significant $(P<0.01)$ relative to body wt.

From the results of Tables 1 and 2 relating to control animals, it is apparent that the Wistar rats differed from the Sprague-Dawley rats in their NAD-pyrophosphorylase activity. Relative to nuclear count, the Wistar rats showed higher activity, whereas relative to body wt. the SpragueDawley rats showed higher activity; thus the ratio (activity of Wistar preparation):(activity of Sprague-Dawley preparation) was 1.33 relative to $10^{9}$ nuclei, and 0.87 relative to $100 \mathrm{~g}$. body wt. In addition to difference of strain, there was also a difference of age in the two groups of rats.

\section{DISCUSSION}

\section{Synthesis of nicotinamide-adenine dinucleotide in liver damage}

Since the NAD-pyrophosphorylase reaction gives results relating to only one of the three steps in the probable synthetic pathway for NAD synthesis in vivo, it follows that a normal level of activity of this enzyme would not exclude impairment of NAD synthesis, but that lowered values would constitute positive evidence of impaired NAD synthesis. Thus the significant decrease in NAD-pyrophosphorylase activity observed after $18 \mathrm{hr}$. treatment with heliotrine led us to conclude that synthesis of NAD was impaired in poisoning with this agent. Although the activity of the enzyme in nuclear preparations from the livers of rats treated with dimethylnitrosamine was still within normal limits at $19 \mathrm{hr}$. relative to nuclear count, impairment of NAD synthesis cannot be excluded for the reason stated above and because the same results were significant relative to another standard. Our results with dimethylnitrosamine were in agreement with those of Stirpe \& Aldridge (1961), even though the dose which we used was twice theirs. We found, however, that heliotrine produced a significant degree of inhibition at $18 \mathrm{hr}$.

Christie \& Le Page (1962a) showed that depression of the NAD and NADP concentrations of liver homogenates was evident $17 \mathrm{hr}$. after heliotrine treatment, and concluded that loss of coenzymes from the liver cells had taken place. The concentrations of liver NAD $4 \mathrm{hr}$. after injection of nicotinamide were also depressed in rats pretreated with heliotrine (Christie \& Le Page, 1962b). The present observations complement these studies and show 
that, in heliotrine poisoning (18 hr.), two factors contribute to the decreased NAD concentrations, namely direct losses from the liver cells and depressed synthesis.

It is possible that, in heliotrine poisoning, NAD synthesis in vivo was more seriously affected than was indicated by the determinations of NAD. pyrophosphorylase activity which were made in vitro under optimum conditions of substrate availability. For example, it is possible that lowered concentrations of nicotinic acid mononucleotide or of ATP may arise by increased loss of, or decreased synthesis of, these precursors. The possibility also exists that the nuclei from the livers of heliotrinetreated rats may have lost some of their NAD pyrophosphorylase during the isolation procedure; however, release of soluble protein from nuclei, isolated from normal liver and suspended in a sucrose medium, does not occur even when the nuclear membranes are ruptured (Barton, 1960).

Because of the considerable proportion of obviously damaged nuclei observed in the nuclear suspensions from the livers of rats treated with heliotrine or with dimethylnitrosamine, it seems possible that the observed decrease in the activity of the enzyme may merely have been an indication of the proportion of severely damaged nuclei in the suspension. This possibility seems unlikely since NAD-pyrophosphorylase activity is unchanged $19 \mathrm{hr}$. after treatment with dimethylnitrosamine.

\section{Significance of observations of nicotinamide-adenine dinucleotide-pyrophosphorylase activity}

We agree with Stirpe \& Aldridge (1961) that a satisfactory technical procedure in the isolation of the nuclei is essential. The unit in which the enzyme activity is expressed also requires careful consideration. With rats of the same age and strain, in which the distribution of the various ploidy groups of the liver cell nuclei can be assumed to be consistent (Christie \& Le Page, 1961), and with the technical precautions mentioned (see Materials and Methods section), nuclear counts were found to be reliable. However, it was considered desirable as a safeguard to employ an independent unit, relative to total liver wt.

From the results expressed relative to nuclear count (Tables 1 and 2) it is apparent that the two groups of rats showed a considerable difference in normal NAD-pyrophosphorylase activity. However, since the two groups also differed in age and strain, we consider it likely that the higher activity of the Wistar rats, expressed relative to nuclear count, may be due to a difference in frequency distribution of the nuclear ploidy groups of the liver cells in the two sets of rats. On the other hand, the Sprague-Dawley rats had a higher total liver NAD. pyrophosphorylase activity expressed per $100 \mathrm{~g}$. body wt. than did the Wistar rats; this may be associated with a higher metabolic activity, characteristic either of the Sprague-Dawley strain or of the younger average age of this group in our experiments.

Branster \& Morton (1956) found differences in the NAD-pyrophosphorylase activity of liver samples from foetal, young and adult mice; their results were expressed relative to nuclear count. However, the differences which they observed could have been largely due to the normal shift of ploidy distribution of nuclei which occurs with age (Vendrely \& Vendrely, 1956), and their results are therefore difficult to interpret without such information for the mouse strain employed.

Waravdekar, Powers \& Leiter (1956) found that the NAD-pyrophosphorylase activity of mouseliver homogenate decreased after the mouse received a tumour transplant. However, activity was expressed relative to $\mathrm{mg}$. of homogenate nitrogen, which may have altered considerably over the experimental period in view of observations which indicate that liver nitrogen may undergo rapid changes of considerable magnitude (Thomson, Heagy, Hutchison \& Davidson, 1953).

Stirpe \& Aldridge (1961) concluded that nuclear NAD-pyrophosphorylase activity decreased in the residual liver left in rats after partial hepatectomy; the activity was expressed relative to protein of the nuclear preparation as estimated by the biuret reaction. However, during the first 3 days after partial hepatectomy, regeneration is rapid (Cater, Holmes \& Mee, 1956), most of the residual liver cells are immediately pre- or post-mitotic, and the possibility exists that relative proportions of the proteins of the nucleus may alter at different phases of the mitotic cycle (Swift, 1950; Heizer, 1955; Richards, 1960). Under such conditions, changes in enzyme activity expressed per mg. of biuret-reacting protein may therefore reflect changes in the amount or type of protein rather than changes in the total amount of the enzyme in the liver tissue of the animal at the time of the experiment. In addition the mean ploidy state may have changed during the experiment.

\section{SUMMARY}

1. Nicotinamide-adenine dinucleotide-pyrophosphorylase activity of preparations of nuclei isolated from the livers of control and heliotrine-treated Wistar rats and of control and dimethylnitrosamine-treated Sprague-Dawley rats has been estimated.

2. The activity as detected by the rate of nicotinamide-adenine dinucleotide synthesis was significantly decreased below the control level in liver-cell nuclei isolated from rats which had been 
treated with heliotrine for $18 \mathrm{hr}$. (or more). There was no significant decrease in rate in the liver nuclei from the rats treated with dimethylnitrossamine (19 hr.) relative to nuclear count.

3. The observations are discussed in relation to present knowledge of nicotinamide-adenine dinucleotide metabolism in liver poisoning.

We wish to express our thanks to Dr L. B. Bull and Dr A. T. Dick of the Animal Health Research Laboratories, C.S.I.R.O., Parkville, Victoria, for supplies of crystalline heliotrine and of Wistar rats of the strain used for the previous studies with heliotrine carried out in this Department. This work was made possible by the financial support of the Anti-Cancer Council of Victoria.

\section{REFERENCES}

Bailie, M. J. (1959). Ph.D. Thesis: University of Melbourne. Bailie, M. J. \& Christie, G. S. (1959). Biochem. J. 72, 473. Barton, A. D. (1960). In The Cell Nucleus, p. 142. Ed. by Mitchell, J. S. London: Butterworth and Co. (Publishers) Ltd.

Branster, M. V. \& Morton, R. K. (1956). Biochem. J. 63, 640.

Cater, D. B., Holmes, B. E. \& Mee, L. K. (1956). Acta radiol., Stockh. 46, 655.

Christie, G. S. (1958). Aust. J. exp. Biol. med. Sci. 36, 413.

Christie, G. S. \& Le Page, R. N. (1961). Lab. Invest. 10, 729.
Christie, G. S. \& Le Page, R. N. (1962a). Biochem. J. 84, 25.

Christie, G. S. \& Le Page, R. N. (1962b). Biochem. J. 84, 202.

Christie, G. S., Le Page, R. N. \& Bailie, M. J. (1961). Nature, Lond., 189, 593.

Hatt, H. (1946). In Organic Syntheses, vol. 2, p. 211. Ed. by Blatt, A. H. London: John Wiley and Sons.

Heizer, P. (1955). Chromosoma, 7, 281.

Hogeboom, G. H. \& Schneider, W. C. (1952). J. biol. Chem. $197,611$.

Hogeboom, G. H., Schneider, W. C. \& Striebich, M. J. (1952). J. biol. Chem. 196, 111.

Horecker, B. L. \& Kornberg, A. (1948). J. biol. Chem. 175, 385.

Kornberg, A. (1950). J. biol. Chem. 182, 779.

Morton, R. K. (1958). Nature, Lond., 181, 540.

Preiss, J. \& Handler, P. (1958a). J. biol. Chem. 233, 488.

Preiss, J. \& Handler, P. (1958b). J. biol. Chem. 233, 493.

Richards, B. M. (1960). In The Cell Nucleus, p. 138. Ed. by Mitchell, J. S. London: Butterworth and Co. (Publishers) Ltd.

Stirpe, F. \& Aldridge, W. N. (1961). Biochem. J. 80, 481.

Swift, H. H. (1950). Physiol. Zool. 23, 169.

Thomson, R. Y., Heagy, F. C., Hutchison, W. C. \& Davidson, J. N. (1953). Biochem. J. 53, 460.

Vendrely, R. \& Vendrely, C. (1956). Int. Rev. Cytol. 5, 171.

Waravdekar, V. S., Powers, O. H. \& Leiter, J. (1956). J. nat. Cancer Inst. 17, 145.

Biochem. J. (1962) 84, 368

\title{
Selective Inhibition by 2-Hepty1-4-hydroxyquinoline $\mathrm{N}$-Oxide of Certain Oxidation-Reduction Reactions
}

\author{
By MARGOT KOGUT AND J. W. LIGHTBOWN \\ Department of Biological Standards, National Institute for Medical Research, London, N.W. 7
}

\section{(Received 20 February 1962)}

The streptomycin antagonist, 2-heptyl-4-hydroxyquinoline $N$-oxide (Lightbown, 1954; Cornforth \& James, 1956), was shown by Lightbown \& Jackson (1956) to be a potent inhibitor of some cytochrome-mediated electron-transport systems. It inhibited the succinoxidase and $\mathrm{NADH}_{2}$ oxidase activities of a Keilin-Hartree heartmuscle preparation at a locus which appeared to be the same as that inhibited by antimycin $A$, namely, it inhibited the oxidation of cytochrome $b$ and the reduction of cytochrome $c$. Very similar effects were observed with Bacillus subtilis and Bacillus pumilis, whereas in Staphylococcus aureus it inhibited the oxidation of cytochrome $b_{1}$ and the reduction of cytochrome $a_{2}$. Experiments designed to localize the effect of the inhibitor showed that it did not inhibit the cytochrome-oxidase activity or the succinate-dehydrogenase activity of heart-muscle preparation, nor was the diaphorase activity of heart-muscle preparation or of bacterial extracts affected. In extracts of Escherichia coli and Proteus vulgaris the reduction of the component which, on spectroscopic evidence, is usually called cytochrome $b_{1}$ was inhibited by this material, though the extent of the inhibition was much less than in the systems mentioned above. Extracts from a fluorescent pseudomonad [strain KB 1 (Kogut \& Podoski, 1953)] which catalysed the oxidation of succinate and malate were relatively insensitive to the inhibitor.

The same compound inhibits light-induced phosphorylation in extracts of Rhodospirillum 